\title{
An Observational Study on Canine-assisted Play Therapy for Children with Autism: Move towards the Phrase of Manualization and Protocol Development
}

\author{
Suk Chun Fung ${ }^{1}$ \\ ${ }^{1}$ Department of Special Education and Counselling, The Education University of Hong Kong, Hong Kong \\ Correspondence: Suk Chun Fung, Department of Special Education and Counselling, The Education University of \\ Hong Kong, Hong Kong, 10 Lo Ping Road, Tai Po, Hong Kong.
}

Received: January 27, 2017 Accepted: February 20, 2017 Online Published: April 6, 2017

doi:10.5539/gjhs.v9n7p67 URL: https://doi.org/10.5539/gjhs.v9n7p67

\begin{abstract}
Canine-assisted play therapy (CAPT) is an emerging psychosocial intervention for children with autism spectrum disorder (ASD). The present case studies used quantitative observation of experimenter-designated behavioral outcomes to examine the effectiveness of a planned CAPT intervention. By utilizing a coding system with typical and ASD-specific behavioral categories, the verbal and non-verbal social behaviors of two elementary-aged children with ASD as well as intellectual and language impairments at pre-treatment, during CAPT treatment, at post-treatment and at follow-up are systematically coded and analyzed. This study took the first steps toward making CAPT treatment manuals and research protocol available to a wider audience. Their publication will assist in standardizing the technique for replication in research and in practice.
\end{abstract}

Keywords: animal-assisted intervention, animal-assisted therapy, autism spectrum disorders, canine-assisted play therapy, observational study

\section{Introduction}

In the past three decades, autism spectrum disorder (ASD) which is characterized by deficits in social communication and restricted, repetitive behaviors (American Psychiatric Association, 2013), has been highlighted as a population that may benefit from animal-assisted therapy (AAT), which is a form of animal-assisted intervention (AAI) (Esposito et al., 2011; Nimer \& Lundahl, 2007). In her review paper, O'Haire (2013) concluded that AAI "is in the first phase of research on new psychosocial interventions for ASD --- proof of concept" (p. 1619). Her analysis is based on the model of Smith et al. (2007), in which four sequential phases of research on psychosocial interventions in autism are identified as follows: (1) Formulation and systematic application of a new intervention; (2) Manualization and protocol development; (3) Efficacy studies; and (4) Community Effectiveness studies. O'Haire (2013) stated that the concept of AAI for certain individuals with ASD has obtained preliminary support from empirical findings. The reported outcomes include an increased frequency and duration of social behaviors (Krs `kova' et al., 2010; Silva et al., 2011), increased socialization (Gabriels et al., 2012; Memishevikj \& Hodzhikj, 2010), and decreased ASD severity in social functioning (Bass et al., 2009; Kern et al., 2011). The preliminary findings suggest that further investigation of AAI for ASD is necessary. There has been a recent growth in empirical studies in this line of research. In the last decade, at least six studies were conducted to systematically review or perform meta-analyses of AAI studies (Berry et al., 2013; Davis et al., 2015; Hoagwood et al., 2016; Maujean et al., 2015; Nimer \& Lundahl, 2007; O'Haire, 2013). Table 1 shows all AAI studies for the ASD population, with the exclusion of two AAI studies using guinea pigs (Krskova et al., 2010; O'Haire et al., 2015), that reviewed or analyzed in these six studies, revealing that most empirical AAI studies were published in the past few years.

AAI for ASD has received growing interest and has recently been the focus of empirical studies. It is a positive development that AAI is becoming more widely recognized within the helping-profession and ASD communities. Currently, the development of AAI is scattered: the types of AAI, targeted populations and outcome measures are all varied (O'Haire, 2013). This is a natural development because AAI is not an independent profession but a practice modality. It is considered an addition to established interventions. Therapy animals can be incorporated into various theoretical frameworks (Chandler, 2011). It is a healthy development to have multi-disciplinary 
helping professionals, such as occupational therapists (Memishevikj \& Hodzhikj, 2010; Sams et al., 2006), certified riding instructors (Gabriels et al., 2015; Lanning et al., 2014), and therapists (Fung \& Leung, 2014; Redefer \& Goodman, 1989), adopt AAI in their therapy sessions and conduct initial efficacy studies. According to the four-phase model (Smith et al., 2007), after initial efficacy studies are performed, the following step is to assemble intervention manuals and establish protocol to implement and evaluate the manualized intervention in subsequent clinical trials. Thus, a focused investigation of AAI for ASD should be prioritized, and the identification of specific types of AAI with clinical significance for treating ASD populations is necessary.

Horses and canines are two animals commonly incorporated into AAI therapy in empirical AAI studies (see Table 1). Equine-assisted activities and therapies (EAAT), which involve horses as part of the therapeutic experience, has been a rapidly growing field for treatment of the ASD population since 2009 (Gabriels et al., 2015). Table 1 shows recent EAAT publications use two main types of interventions: equine assisted therapies (EAT) and equines assisted activities (EAA) for working with the ASD population. The reviewed EAA studies included studies of therapeutic horseback riding (THR) (Bass et al., 2009; Gabriels et al., 2012; Gabriels et al., 2015; Garcia-Gomez et al., 2014; Jenkins \& DiGennaro Reed, 2013), a study of psychoeducational horseback riding (PER) (Keino et al., 2009), and two other EAA studies (Kern et al., 2011; Lanning et al., 2014); whereas the reviewed EAT studies included the hippotherapy study of Taylor et al., (2009) and the study of Memishevikj \& Hodzhikj (2010). It seems that there is a growing trend of using THR in ASD intervention. The definition of THR — "an equine-assisted activity for the purpose of contributing positively to the cognitive, physical, emotional and social well-being of individuals with special needs"-and other EAAT methods can be found on the website of the Professional Association of Therapeutic Horsemanship International (2016). Standardized THR is typically led by a certified THR instructor to teach therapeutic riding skills (e.g., mounting, halting, steering, turning, and trotting) and horsemanship skills (e.g., how to lead and care for horses) in small riding group settings (Gabriels et al., 2015). As shown in Table 1, the number of sessions (9 to 12), the frequency of sessions (mostly once a week), and the duration of each session (mostly 60 minutes) of THR are standardized. In addition, it is found that surveys are the main type of assessment used in EAAT studies. Standardized instruments such as the Social Responsiveness Scale (Bass, 2009; Gabriels et al., 2015), the Aberrant Behavior Checklist-Community (ABC-C), Vineland Adaptive Behavioral Scales-2nd Edition (VABS-II), Bruininks-Oseretsky Test of Motor Proficiency-2nd Edition (BOT-2) (Short Form), and the Sensory Integration and Praxis Tests (SIPT) (Gabriels et al., 2012; Gabriels et al., 2015) have been used in more than one EAAT study.

In contrast to EAAT studies, the presentation of canine-assisted activities and therapies (CAAT), which involve canines as part of the therapeutic experience, is obviously varied in terms of the terminology, manualization, and research protocol. As shown in Table 1, many different terms - such as pet-facilitated therapy (Redefer \& Goodman, 1989), animal-assisted therapy (Martin \& Farnum, 2002), occupational therapy with animals (Sams et al., 2006), service dogs (Burrows et al., 2008; Viau et al., 2010), therapy dogs (Solomon, 2010), canine-assisted therapy (Silva et al., 2011) and animal-assisted play therapy (Fung \& Leung, 2014) - have been used in CAAT studies. In addition to the varied terminology, no study has replicated standardized programs from another CAAT study (see Table 1). Within nine CAAT studies in Table 1, canine-assisted play therapy (CAPT) (Fung \& Leung, 2014; Issacs, 1998; Redefer \& Goodman, 1989; Silva et al., 2011) and service-dog home placement or home visits (Burrows et al., 2008; Solomon 2010; Viau et al., 2010) are found to be main intervention forms; however, most of these CAAT programs were only briefly described (Issacs, 1998; Martin \& Farnum, 2002; Redefer \& Goodman, 1989; Sams et al., 2006; Silva et al., 2011; Solomon, 2010). Some studies contained no program description (Burrows et al., 2008; Viau et al., 2010). Moreover, the duration of the CAPT (from 6 to 15 weeks), the number of sessions (from 2 to 18), and the length of each session (from 15 to 45 minutes) all varied, and there were no standard research protocols in the CAAT studies. As shown in Table 1, the major type of assessment in CAAT studies is behavioral coding (Fung \& Leung, 2014; Issacs, 1998; Martin \& Farnum, 2002; Redefer \& Goodman, 1989; Sams et al., 2006; Silva et al., 2011). However, no uniformed coding system is available. The coding time is also varied in the observational CAAT studies shown in Table 1, ranging from 3 minutes to 25 minutes. In short, CAAT studies have enlisted a wide range of terminology, treatment activities and coding methods. 
Table 1. CAAT and EAAT Studies for ASD included in the Current Six Systematic Review and Meta-analysis Studies

\begin{tabular}{|c|c|c|c|c|c|c|c|}
\hline \multirow[b]{2}{*}{ First Author } & \multirow[b]{2}{*}{$\begin{array}{c}\text { AAI } \\
\text { Terminology }\end{array}$} & \multirow[b]{2}{*}{$\begin{array}{l}\text { Intervention } \\
\text { Form }\end{array}$} & \multicolumn{2}{|c|}{ Treatment Manual } & \multicolumn{3}{|c|}{ Outcome Measures } \\
\hline & & & 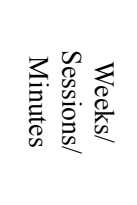 & 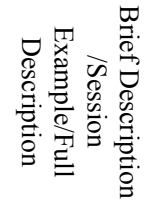 & $\begin{array}{l}\text { Assessment } \\
\text { Types }\end{array}$ & Coding Category/Standardized Instruments & 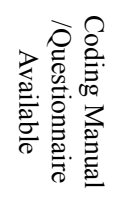 \\
\hline \multicolumn{8}{|c|}{ Canine-assisted Activity and Therapy (CAAT) } \\
\hline $\begin{array}{l}\text { Redefer } \\
(1989)\end{array}$ & $\begin{array}{l}\text { Pet-facilita } \\
\text { ted therapy }\end{array}$ & $\begin{array}{l}\text { Canine-assi } \\
\text { sted play } \\
\text { therapy }\end{array}$ & $-/ 18 / 20$ & $\checkmark / \mathrm{X} / \mathrm{X}$ & $\begin{array}{l}\text { Behavioral } \\
\text { Coding } \\
(5 \text { minutes } \\
\text { coding })\end{array}$ & $\begin{array}{l}\text { Isolation } \\
\text { Social interaction }\end{array}$ & $\mathrm{X}$ \\
\hline $\begin{array}{l}\text { Issacs } \\
(1998)\end{array}$ & $\begin{array}{l}\text { Pet-facilita } \\
\text { ted therapy }\end{array}$ & $\begin{array}{l}\text { Canine-assi } \\
\text { sted play } \\
\text { therapy }\end{array}$ & $-/ 9 / 25$ & $\checkmark / \mathrm{X} / \mathrm{X}$ & $\begin{array}{l}\text { Behavioral } \\
\text { Coding } \\
(25 \text { minutes } \\
\text { coding })\end{array}$ & $\begin{array}{l}\text { Social verbal, social nonverbal, social } \\
\text { negative, and reciprocal interaction }\end{array}$ & $\checkmark$ \\
\hline $\begin{array}{l}\text { Martin } \\
(2002)\end{array}$ & $\begin{array}{l}\text { Animal-ass } \\
\text { isted } \\
\text { therapy }\end{array}$ & $\begin{array}{l}\text { Elicit } \\
\text { prosocial } \\
\text { behaviors } \\
\text { by asking } \\
\text { questions }\end{array}$ & $15 / 15 / 15$ & $\checkmark / \mathrm{X} / \mathrm{X}$ & $\begin{array}{l}\text { Behavioral } \\
\text { Coding } \\
(3 \quad \text { minutes } \\
\text { coding })\end{array}$ & $\begin{array}{l}\text { (1) Behaviors: Hand flapping; } \\
\text { Touching experimental object; Giving } \\
\text { treats; Laughing; Looking at } \\
\text { therapist/at object/around the room. (2) } \\
\text { Verbalizations: Respond to questions } \\
\text { with detailed explanations; talk about } \\
\text { therapist/self/experiment object; talk to } \\
\text { experimental object; talk about } \\
\text { unrelated topics; answer a request } \\
\text { "yes"; ignoring a question followed by } \\
\text { an unrelated statement. }\end{array}$ & $\mathrm{X}$ \\
\hline $\begin{array}{l}\text { Sams } \\
(2006)\end{array}$ & $\begin{array}{l}\text { Occupation } \\
\text { al therapy } \\
\text { with } \\
\text { animals }\end{array}$ & $\begin{array}{l}\text { Canine-assi } \\
\text { sted } \\
\text { occupationa } \\
1 \text { therapy }\end{array}$ & $\begin{array}{l}15 / 2-12 / \\
M=28.5\end{array}$ & $\checkmark / \mathrm{X} / \mathrm{X}$ & $\begin{array}{l}\text { Behavioral } \\
\text { Coding } \\
(13 \text { sessions })\end{array}$ & $\begin{array}{l}\text { Prompted/spontaneous language use } \\
\text { Prompted/spontaneous } \\
\text { interaction }\end{array}$ & $\checkmark$ \\
\hline $\begin{array}{l}\text { Burrows } \\
(2008)\end{array}$ & $\begin{array}{l}\text { Service } \\
\text { dog }\end{array}$ & $\begin{array}{l}\text { service-dog } \\
\text { home } \\
\text { placement }\end{array}$ & $\begin{array}{l}24-48 / \mathrm{n} / \\
\mathrm{a} / \mathrm{n} / \mathrm{a}\end{array}$ & $\mathrm{X} / \mathrm{X} / \mathrm{X}$ & $\begin{array}{l}\text { Interviews \& } \\
\text { Direct } \\
\text { Observation }\end{array}$ & $\mathrm{X}$ & $X$ \\
\hline $\begin{array}{l}\text { Solomon } \\
(2010)\end{array}$ & $\begin{array}{l}\text { Therapy } \\
\text { dog } \\
\text { Service } \\
\text { dog }\end{array}$ & Home visits & $\begin{array}{l}4-6 / 4-6 / 6 \\
0-120\end{array}$ & $\checkmark / \mathrm{X} / \mathrm{X}$ & $\begin{array}{l}\text { Observation, } \\
\text { Interview }\end{array}$ & $\mathrm{X}$ (Anecdotal reports) & $\mathrm{X}$ \\
\hline $\begin{array}{l}\text { Viau } \\
(2010)\end{array}$ & $\begin{array}{l}\text { Service } \\
\text { dog }\end{array}$ & $\begin{array}{l}\text { service-dog } \\
\text { home } \\
\text { placement }\end{array}$ & $4 / \mathrm{n} / \mathrm{a} / \mathrm{n} / \mathrm{a}$ & $\mathrm{X} / \mathrm{X} / \mathrm{X}$ & $\begin{array}{l}\text { Survey; } \\
\text { Measure } \\
\text { Basal Cortisol }\end{array}$ & $\mathrm{X}$ & $\mathrm{X}$ \\
\hline $\begin{array}{l}\text { Silva } \\
(2011)\end{array}$ & $\begin{array}{l}\text { Canine-ass } \\
\text { isted } \\
\text { therapy }\end{array}$ & $\begin{array}{l}\text { Structured } \\
\text { one-to-one } \\
\text { activities }\end{array}$ & $6 / 6 / 45$ & $\checkmark / \mathrm{X} / \mathrm{X}$ & $\begin{array}{l}\text { Behavioral } \\
\text { Coding } \\
(15 \text { minutes } \\
\text { coding })\end{array}$ & $\begin{array}{l}\text { (1) Negative behaviors: Physical } \\
\text { aggressive behavior toward the } \\
\text { therapist; physical aggressive behavior } \\
\text { toward inanimate objects; verbal } \\
\text { aggressive behavior; repetitive } \\
\text { smelling; obsessive sraring; grabbing } \\
\text { behavior; self-absorption. (2) Positive } \\
\text { behaviors: Affectionate behavior; play; } \\
\text { visual contact; smiling }\end{array}$ & $\checkmark$ \\
\hline $\begin{array}{l}\text { Fung } \\
(2014)\end{array}$ & $\begin{array}{l}\text { Animal-ass } \\
\text { isted play } \\
\text { therapy }\end{array}$ & $\begin{array}{l}\text { Canine-assi } \\
\text { sted play } \\
\text { therapy }\end{array}$ & $5 / 14 / 20$ & $\checkmark / \checkmark / X$ & $\begin{array}{l}\text { Behavioral } \\
\text { Coding } \\
(20 \quad \text { minutes } \\
\text { coding })\end{array}$ & $\begin{array}{l}\text { (1) Social Behavior: Social Non-Verbal } \\
\text { Behavior (Eye Contact, Touch, } \\
\text { Following Instructions, Joint Attention, } \\
\text { Imitation, Wait, Initiation, Response) \& } \\
\text { Social Verbal Behavior (Questioning, } \\
\text { Verbal Response, Verbal Imitation, } \\
\text { Expression of Needs, Sharing); (2) } \\
\text { Non-social Behavior (Isolation, } \\
\text { Autistic Features, Negative Behavior); } \\
\text { (3) Others; and (4) Not observed. }\end{array}$ & $X$ \\
\hline
\end{tabular}




\begin{tabular}{|c|c|c|c|c|c|c|c|}
\hline \multicolumn{8}{|c|}{ Equine-assisted Activity and Therapy (EAAT) } \\
\hline Bass (2009) & THR & THR & $12 / 12 / 60$ & $\mathrm{X} / \mathrm{X} / \checkmark$ & Survey & $\begin{array}{l}\text { Social Responsiveness Scale (SRS); } \\
\text { SP. }\end{array}$ & $\mathrm{X}$ \\
\hline $\begin{array}{l}\text { Keino } \\
(2009)\end{array}$ & $\begin{array}{l}\text { Psycho-ed } \\
\text { ucational } \\
\text { horseback } \\
\text { riding }\end{array}$ & $\begin{array}{l}\text { Psycho-edu } \\
\text { cational } \\
\text { horseback } \\
\text { riding }\end{array}$ & $\begin{array}{l}48-148 / \\
-/-\end{array}$ & $\checkmark / \mathrm{X} / \mathrm{X}$ & Survey & HEIM & $\checkmark$ \\
\hline $\begin{array}{l}\text { Taylor } \\
(2009)\end{array}$ & $\begin{array}{l}\text { Hippothera } \\
\text { py }\end{array}$ & $\begin{array}{l}\text { Hippothera } \\
\text { py }\end{array}$ & $16 / 16 / 45$ & $\checkmark / \mathrm{X} / \mathrm{X}$ & Observation & PVQ & $\mathrm{X}$ \\
\hline $\begin{array}{l}\text { Memishevik } \\
\text { j (2010) }\end{array}$ & EAT & EAT & $10 / 10 / 30$ & $\checkmark / \mathrm{X} / \mathrm{X}$ & Survey & $\begin{array}{l}\text { Autism Treatment Evaluation Checklist } \\
\text { (ATEC) }\end{array}$ & $\mathrm{X}$ \\
\hline Kern (2011) & EAA & EAA & $24 / 24 / 60$ & $\checkmark / \mathrm{X} / \mathrm{X}$ & Survey & CARS; QLES-Q; SP; TPCIS. & $\mathrm{X}$ \\
\hline $\begin{array}{l}\text { Gabriels } \\
(2012)\end{array}$ & THR & THR & $10 / 10 / 60$ & $\checkmark / \mathrm{X} / \mathrm{X}$ & Survey & $\begin{array}{l}\text { ABC-C; VABS-II; BOT-2, Short Form; } \\
\text { SIPT. }\end{array}$ & $\mathrm{X}$ \\
\hline $\begin{array}{l}\text { Jenkins } \\
(2013)\end{array}$ & THR & THR & $9 / 9 / 60$ & $\mathrm{X} / \mathrm{X} / \mathrm{X}$ & $\begin{array}{l}\text { Observation; } \\
\text { Survey }\end{array}$ & $\begin{array}{l}\text { CBCL/6-18; TRF; Bruininks-Oseretsky } \\
\text { Test of Motor Proficiency, second } \\
\text { edition. }\end{array}$ & $\mathrm{X}$ \\
\hline $\begin{array}{l}\text { Garcia-Gom } \\
\text { ez (2014) }\end{array}$ & THR & $\begin{array}{l}\text { Adapted } \\
\text { THR }\end{array}$ & $\begin{array}{l}12 \\
/ 24 / 45\end{array}$ & $\checkmark / \mathrm{X} / \mathrm{X}$ & Survey & $\begin{array}{l}\text { BASC-T (for Teachers) test battery; } \\
\text { Quality-of-Life Model. }\end{array}$ & $\mathrm{X}$ \\
\hline $\begin{array}{l}\text { Lanning } \\
\text { (2014) }\end{array}$ & EAA & EAA & $12 / 12 / 60$ & $\checkmark / \mathrm{X} / \mathrm{X}$ & Survey & PedsQL; CHQ. & $\mathrm{X}$ \\
\hline $\begin{array}{l}\text { Gabriels } \\
(2015)\end{array}$ & THR & THR & $10 /--/ 45$ & $\checkmark / X / X$ & Survey & $\begin{array}{l}\text { PPVT-4; SALT; BOT-2, Short Form; } \\
\text { SIPT; Praxis on Verbal command and } \\
\text { Postural Praxis; SRS; } \\
\text { VABS-II; ABC-C. }\end{array}$ & $\mathrm{X}$ \\
\hline
\end{tabular}

As demonstrated by the literature reviewed, in EAAT studies, THR is a structured riding program that has been increasingly implemented and measured in recent years (Bass et al., 2009; Gabriels et al., 2012; Gabriels et al., 2015; Garcia-Gomez et al., 2014; Jenkins \& DiGennaro Reed, 2013; Lanning et al., 2014). CAPT can be identified as the main intervention form of CAAT studies. It is proposed that a focused effort to work on EAAT and CAAT, specifically THR and CAPT, could increase the pace of AAT development and guide it into the second phase of research on psychosocial intervention in autism. In recent years, the development of THR has been rapidly growing. The literature has shown that unified terminology, standardized intervention manuals and standardized instruments have been used in THR studies for the ASD population (Bass et al., 2009; Gabriels et al., 2012; Gabriels et al., 2015; Garcia-Gomez et al., 2014; Jenkins \& DiGennaro Reed, 2013; Lanning et al., 2014). In this regard, the development of CAPT is obviously slower than that of THR. At present, the CAPT is still experiencing scattered development, which can largely be explained by the absence of treatment manuals and standard research protocols for both clinical use and continued research. The many possibilities for utilizing canines in different play contexts and different settings make CAPT more difficult than THR to establish as a standardized intervention for ASD populations. However, trained canines, who are non-judgmental audiences, speech elicitors, younger siblings, and comfort companions (Fung, 2016), make CAPT an interactive intervention that had been evidenced as initial efficacy treatment for children with ASD (for example, Redefer \& Goodman, 1989; Fung \& Leung, 2014). As suggested by Smith et al., (2007) a decade ago, the priorities in ASD research should include initial efficacy studies on interventions for core features of ASD, such as social reciprocity and preparation for efficacy and effectiveness trials, by developing manuals for interventions that have shown promise. The development of a CAPT treatment manual and research protocol should be prioritized in ASD research.

The present study contains case studies that were part of a larger project to compare the CAPT intervention to an intervention in which a baby doll was the substitute object. The results of this randomized controlled trial, which has been published (Fung \& Leung, 2014) and included in a recent AAT review paper (Hoagwood et al., 2016), showed that the CAPT intervention produced small but statistically significant increases in the verbal social behavior of children with autism, whereas the comparison intervention did not (Fung \& Leung, 2014). Given that a single case study has the unique ability to present a detailed intervention, the case studies were planned to achieve two aims. The first was to explore the explicit effects of a structured CAPT on the verbal and non-verbal social behavior of two boys with ASD by evaluating their social behavior at pre-treatment, during treatment, at post-treatment and in follow-up phases. The second was to include and examine a CAPT manual and coding system to help establish a standardized intervention manual and research protocol. The aims were directed towards a strategic move from the "formulation and systematic application of a new intervention" phase to the "manualization and protocol development" phase. 


\section{Method}

The current study was approved by the Research Ethics Committee of the Chinese University of Hong Kong.

\subsection{Participants}

Two elementary school-aged students, Leon and William (pseudonyms), who were identified as meeting the Diagnostic and Statistical Manual of Mental Disorders IV (American Psychiatric Association, 1994) criteria for ASD and had no other specific psychiatric disorder(s), were selected for a randomized controlled trial that set out to compare the CAPT intervention with a comparison intervention. They were recruited from a special school in Hong Kong that enrolls primary and secondary students with mild intellectual disabilities. Their participation was voluntary, and the objectives of the study were clearly explained in the invitation letter. Consent for the acquisition of students' personal data was requested. Their personal data included reports of clinical psychologists and school speech therapists. Prior to the start of the study, the parents/guardians of the two students agreed to the terms of the study through written informed consent. Leon and William had no pet canines at home and were assessed using a Chinese version of "Client Screening Form for AAT" (Chandler, 2011) to identify any circumstances that would preclude their participation. Both boys were suitable for CAPT intervention. At the time of the intervention, they were receiving no other treatment.

Leon was a 10-year-old boy whose intellectual functioning was estimated to be within the low-mild range of mental deficiency based on his performance on the Stanford-Binet Intelligence Scales (SB5). The above mentioned assessments were conducted by a clinical psychologist in a government-funded child assessment center in Hong Kong. He presented a mild delay in verbal skills, as assessed by a speech therapist at his school using the Reynell Development Language Scale. Leon achieved the comprehension and expression ability of non-standardized language around the age of 4 years. At the time of the assessment, he could use three-word phrases to talk about and ask for things spontaneously. During the baseline sessions, Leon was not interested in any play materials. While his verbal behavior was frequent, his speech was confusing and out of context. He seldom exhibited stereotypic autistic behaviors or negative behaviors.

William was an eight-year-old boy who was also assessed to be within the low-mild range of mental deficiency at a Hong Kong government-funded child assessment center. William presented a moderate delay in verbal ability. He achieved the comprehension ability of non-standardized language around the age of 2 years and 9 months and the expression ability of non-standardized language around the age of 3 years. At the time of the assessment, he could use mostly two-word phrases and some three-word phrases to talk about and ask for things spontaneously. Direct observation revealed that he exhibited few social behaviors and maintained a flat affect during the baseline sessions. As Leon did, William also seldom elicited stereotypic autistic behaviors or negative behaviors.

\subsection{Procedures}

All 23 videotaped sessions with Leon were held in a multipurpose room at his school. Before and immediately after the 14 CAPT treatment sessions, Leon's naturally occurring social behaviors were measured in 3 baseline sessions and 3 posttreatment sessions. Finally, 3 follow-up sessions were conducted by an unfamiliar adult to examine the maintenance of the treatment effect at one month posttreatment.

\subsection{Intervetnion}

The treatment approach in the current study was CAPT, in which a therapy canine was incorporated into a play context. CAPT was implemented with one participant, one interventionist, and a therapy canine in 20-minute sessions held 3 times per week. A manualized protocol that included session-by-session and step-by-step procedures was developed in this study (Table 2).

The treatment had a structured nature, i.e., a fixed location, a fixed time schedule, structured organization and standard dialogues. The 14 sessions were structured in 4 phases: (1) 2 sessions that involved the building of the child-canine relationship, with the assistance of the therapist; (2) 5 sessions that involved child-canine-therapist interactions; (3) 5 sessions that involved child-therapist interactions in the presence of the canine; and (4) 2 sessions that involved child-therapist interactions with a diminishing presence of the canine. Each session was structured into 3 parts: introduction, play time and closing. The therapist started each session by (1) greeting the child ("Hello, Leon."); (2) introducing herself to the child and prompting the child to greet her ("I am Ms. XX. Say, Hello, Ms. XX"); (3) prompting the child to greet the canine and showing the canine's name card ("She is Coco. Say, Hello, Coco."); (4) attach the name tags onto the clothes of the child and herself; (5) tells the child the two of them will be playing with the canine in the session ("Today, Coco, Ms. XX and you are going to play activities together here."); and (6) swinging a small musical instrument to mark the beginning of the activity time ("The time for play starts!"). In the last minute of each session, the therapist (1) ends the session by saying, "The play 
time is up for today. Let's put the play materials onto the box!" (2) praises the child if the child puts the play materials into the box: "Good! You are a good child!" (3) tells the child to come back next time- "See you on (the date)"-with visual support (showing the child the date of the next session); (4) asks the child to say goodbye to the canine, i.e., "Say goodbye to Coco. She will play with us next time", and (5) ending the session by swinging the small musical instrument again and then saying, "Goodbye. See you next time!"

Another characteristic of CAPT is the interactive nature. In line with the study objectives, the play activities were selected and designed to facilitate the social interaction of the participant. A variety of ball games - small ball, bowling, basketball and balloon toss-were frequently used in the treatment. Some non-physical games, such as brick tower building and puzzle playing, were also selected to achieve a balance between physical games and non-physical games. Moreover, the activities were introduced step by step to cater to the play skills and the motivation of children with autism. For example, in phase two, the therapist first introduced easy activities, such as "combing hair", and then introduced higher-skill activities, such as "going for a walk and buying fruits". Finally, the therapist displayed all toys the child had played with and let the child choose the activities he wanted. Turn-talking was emphasized in this CAPT intervention.

Table 2. A Canine-assisted Play Therapy Treatment Manual

Phase 1 objectives (Sessions 4 \& 5) 1) To make direct contact with the therapy canine and 2) to build the child-canine relationship with the assistance of the therapist.

\section{Sessions Activities}

$4 \quad$ Activity 1: Name body parts $(6 \mathrm{~min}$.): Introduce the canine to the child by naming the dog's body parts: eyes/ears/nose/mouth.

Activity 2: Clean the canine and feed it water (6 min.): Tell the child that the canine is going to drink water. Ask the child to clean the canine's face, hands and feet (give the child tissue). Then, hold the canine and let the child give it water (give the child water). Praise the child for taking care of the canine.

Activity 3: Pet the canine (6 min.): Tell the child that the canine is going to sleep, and ask the child to pet the canine.

$5 \quad$ Activity 1 : Identify body parts (6 min.): Ask the child to identify the body parts of the canine, with both of you pointing at the different body parts. Praise the child when he/she is able to point at the body part.

Activity 2: Clean the canine and feed it water and treats ( $6 \mathrm{~min}$.): Tell the child that the canine is going to eat food and drink water. Ask the child to clean the canine's face, hands and feet (give the child tissue). Then, hold the canine and let the child give it a treat (give the child a small treat) and then water (give the child water). Praise the child for taking care of the canine.

Activity 3: Pet the canine ( $6 \mathrm{~min}$.): Tell the child that the canine is going to sleep. Ask the child to pet the canine.

Phase 2 objectives (Sessions 6 to 10) 1) To involve the child in child-canine-therapist interactive activities and 2) to emphasize turn-taking in the interactive activities.

\section{Sessions Activities}

6 Activity 1: Comb hair (9 min.) Show the child a comb and demonstrate combing the canine's hair. Then, ask the child to comb its hair. Repeat the sequence 2 times. Then, comb the child's hair (use another comb). Have him/her comb your hair. Repeat the sequence several times until time is up.

Activity 2: Go for a walk (9 min.) Show the child a canine leash and tell the child to bring the canine for a walk. Demonstrate and then ask the child to walk the canine. The child and you take turns in the activity until time is up.

Activity 1: Go for a walk and buy fruit ( 9 min.): Show the child a canine leash and tell the child to bring the canine for a walk. Demonstrate and then ask the child to walk the canine. The child and you take turns in the activity several times. Then, ask the child to bring the canine for a walk and pretend to buy some fruit. Let the child play with the canine as you set up the toy fruits.

Activity 2: Football game (9 min.): Show the child a ball and tell the child to play football. Use the canine's leg to kick the ball to the child. Ask the child to hold the ball and throw the ball back to you. Repeat the sequence several times. Do not remind the child to throw the ball back unless the child does not throw it back within 2 minutes. Repeat the game until time is up. 
$8 \quad$ Activity Free choice (18 min.): Tell the child that there are several activities available in this session. They are: clean the canine and feed it water and treats, comb its hair, go for a walk, go for a walk and buy fruit, and play football. Ask the child to choose an activity he/she likes to play. If the child does not respond, take the initiative to choose an activity. Follow the pace and interest of the child. Let the child take the initiative in the process. It is fine to change or not to change activities throughout the session. Emphasize turn-taking in the interactive activities.

9 Activity Bowling game (18 min.): Tell the child that the canine and you are going to play bowling. Start the activity with the therapy canine. Ask the child to play after you. You and the child take turns in the activity. Give positive reinforcement to the child in the process.

10 Activity Free choice (18 min.): tell the child that there are several activities available in this session. They are: clean the dog and feed it water and treats, comb its hair, go for a walk, go for a walk and buy fruit, play the football game or play bowling. Ask the child to choose an activity he/she likes to play. If the child does not respond, take the initiative to choose an activity. Follow the pace and interest of the child. Let the child take the initiative in the process. It is fine to change or not to change activities throughout the session. Emphasize turn-taking in the interactive activities.

Phase 3 objectives: (Sessions 11 to 15) 1) To facilitate child-therapist interactions in the presence of the canine and 2) to emphasize turn-taking in the interactive activities.

Sessions Activities

11 Activity 1: Basketball game (9 min.): Show a basketball game to the child. Demonstrate the way to play and teach the child to stand beside the canine and throw the ball. Ask the child to pick up the ball and give it to you. Thank the child when he/she does what you say. Take turns and repeat the game until time is up.

Activity 2: Puzzle game ( 9 min.): Show the child a puzzle. Tell the child to sit with the canine and give the child the puzzle frame. Sit in front of the child and ask the child which piece of the puzzle he/she would like to have. Choose a piece of puzzle if there is no response from the child. Put the chosen puzzle onto a toy car and push the car toward the child. The child is supposed to put the piece of puzzle onto the frame. Provide a picture of the puzzle set as visual support. Then, ask the child to push the car back. Again, ask the child to choose a piece of the puzzle. Repeat the sequence until the puzzle is finished. In the next round, use another puzzle. In this round, do not give verbal instructions, i.e., "Push the car to me". If the child does not push the car to you or show the desire for a piece of puzzle after 10 seconds, give verbal support. Repeat the game until time is up.

12 Activity 1: Puzzle game (9 min.): The same procedure as described in Session 8.

Activity 2: Musical instruments (9 min.): Show the child a toy guitar, a toy celesta and a toy peddler's drum. Ask the child to play music for the canine. Teach the child a simple number song and show him/her the lyrics as visual support ('number song': 1, 2, 3; 3, 2, 1; 1, 2, 3, 4, 5, 6, 7; 2, 3, 4; 4, 3, 2; 4, 5, 6, 7, 8, 9, 10). Ask the child to sing the song with you, but it is ok for the child not to sing. Let the child play with the instruments until time is up. Continue telling the child that the canine is a listener.

13 Activity 1: Balloon game (9 min.): Show the child an inflated balloon to attract his/her attention. Give the child a deflated balloon, a felt pen and colored stickers. Help the child to blow up a balloon if he/she is not able to do it alone. Ask the child about his/her preference for the balloon's size. Let the child draw anything he/she likes on the balloon. If the child does not have any idea, show him/her yours as a sample to imitate. After drawing, ask the child to play with the balloon, such as playing volleyball, with you. Play the game until the time is up.

Activity 2: Fishing game (9 min.): Show the child a fishing game. Ask the child to fish for a targeted object and then put it in a plastic bag. Praise the child if he/she follows your request. Ask the child to fish for different objects until time is up.

14 Activity 1: Stack brick tower game $(9 \mathrm{~min}$.): Show the child the brick tower game. Take turns with the child to build a tower of bricks in multiple levels. After a tower is built, take turns with the child to remove a brick from one level. Throw dice to decide the color of the brick. Then, add the brick to the top of the tower to build new levels until the tower collapses. You start first to show how to play. Adjust and simplify the way of playing to fit the cognitive level and interest of the child. Play this game until time is up.

Activity 2: Basketball game (9 min.): Show a basketball game to the child. Ask the child to stand beside the canine and throw the ball. Ask the child to pick up the ball and give it to you. Thank the child when he/she does what you ask. Take turns playing the game until time is up. 
15 Activity 1: Free choice (17 min.): Show the child all play materials: basketball game, puzzle game with toy car, musical instruments, and fishing game. Ask the child to choose the activity he/she would like to play. Wait 10 seconds for the child's reply. Choose one of the activities in case there is no response from the child. The child may shift to play another game whenever he/she likes. Emphasize turn taking in the play process.

Activity 2: Photo-taking ( $1 \mathrm{~min}$.): Tell the child there are 2 minutes left for this session and that the canine will not be present in the next session. Say that you will take a photo of the child together with the canine and that the photo will be given to the child later. Ask the child to sit with the canine. Take the photo of them, and show the child the camera and the image.

Phase 4 objectives (Sessions $16 \&$ 17) 1) To maintain child-therapist interactions with the diminishing presence of the canine and 2) to emphasize turn-taking in interactive activities.

Sessions Activities

16 Activity 1: Balloon game (9 min.): the same procedure as described in Session 10.

Activity 2: Chess game (9 min.): Show the child a chess game set. Demonstrate how to play: (1) Throw the two dice, (2) identify the color and shape and then find the right chess piece, and (3) put the right chess piece into the chessboard. Ask the child to take turns in the game. Praise the child when he/she is able to identify the right chess piece and/or put the chess into the correct position on the chessboard. Take turns playing the game until time is up.

17 Activity 1: Drawing (9 min.): Show the child a large piece of drawing paper and a drawing kit. Use a shape mold to outline an object (e.g., a house) on the paper and invite the child to color the object. Show the child a picture of the object as visual support. Let the child use a shape mold to outline any object and color the drawing. Let the child draw anything he/she likes.

Activity 2: Spinning top swirling game (9 min.): Show the child another game: a spinning top game. Show the child how to spin the top. Let the child try to spin the top. Take turns in this game until time is up.

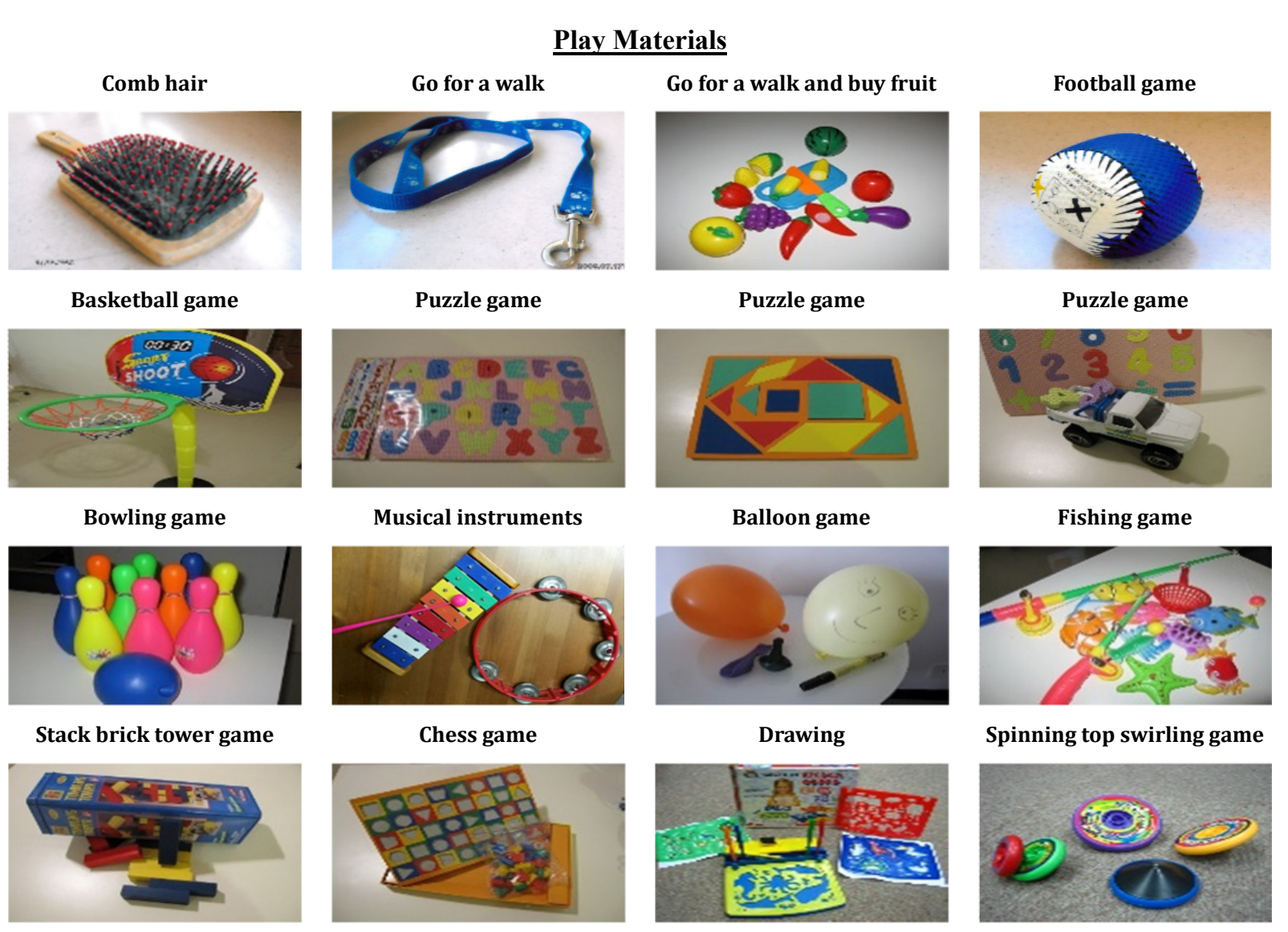




\subsection{Interventionist}

The current case study was conducted by a female therapist. She had received post-graduate training in counseling and had earned certificates in the following courses: 1) Delta Society Pet Partners Team Training Course (Introductory Workshop); 2) Delta Society AAT Applications I Course (Advanced Workshop); and 3) Animal Assisted Therapy Training Program (Advanced Workshop), provided by the Center for Animal Assisted Therapy at the University of North Texas.

Coco, a 9-year-old female golden retriever, was recruited from the Animal Asia Foundation to participate in the study. Coco was a qualified and experienced therapy canine. She had been neutered and had passed assessments of temperament, basic obedience skills, and the ability to cope with stress.

\subsection{Outcome Measures}

An A-B-A single-subject design, which provides individual participant response profiles and allows inferences about causes of change at the individual level, was employed to examine treatment effectiveness (Nugent, 1996). Prior to the CAPT treatment, the naturally occurring social behaviors of Leon and William were measured in three baseline sessions. Assessments were then performed over 14 treatment sessions in four phases and again during three posttreatment sessions that occurred immediately after the intervention ended. Three follow-up assessments were performed at one month posttreatment, and they were conducted by an unfamiliar adult to examine the maintenance of the treatment effect.

\subsection{Coding}

The effects of CAPT were assessed as a function of the frequency of social behaviors exhibited across four stages: A: baseline (sessions 1-3), B: treatment (sessions 4-17), A: post-treatment (sessions 18-20), and A: follow-up (sessions $21-23$ ). A coding system with a coding manual was created with an operationalized definition of each behavioral category (Table 3). There were 4 behavioral categories: social behavior (SB), non-social behavior (NSB), others, and not observed. SB was broken down into two sub-categories of behaviors: social non-verbal behavior (SNVB) and social verbal behavior (SVB). The SNVB and SVB were further broken down into specific items (see Table 3). This coding system included many typical behavioral categories that were also included in other CAPT studies (e.g., Sams et al., 2006; Silva et al., 2011), such as negative behavior, touch, and eye contact. Some ASD-specific behavioral categories, such as joint attention, isolation, and autistic features, were created with operationalized definitions in the current coding system. All twenty-three 20-minute sessions were systematically coded using momentary time sampling to estimate the frequency of the targeted behaviors using a 15 -second interval, which is a typical time frame in this type of research (Kennedy, 2005).

The natural occurrence of Leon and William's social behavior was measured at the baseline, posttreatment and follow-up stages. During these stages, each session consisted of 5 parts: (1) introduction (1 min.: content as shown in Intervention section); (2) free play, therapist-passive condition (6 min.: the therapist did not initiate play but responded to Leon's initiation); (3) free play, therapist-active condition (6 min.: the therapist initiated play); (4) free play, therapist-passive condition (6 min.); (5) closing (1 min.: content as shown in Intervention section). During the treatment stage, Leon's social behavior in responding to or addressing the therapist and the therapy canine were measured.

Table 3. A Canine-Assisted Play Therapy Coding Manual

\begin{tabular}{llll}
\hline Categories & Sub-categories & Items & Definitions \\
\hline $\begin{array}{l}\text { 1. Social } \\
\text { Behavior }\end{array}$ & $\begin{array}{l}\text { Social } \\
\text { (SB) }\end{array}$ & $\begin{array}{l}\text { Ene } \\
\text { Behavior } \\
\text { (SNVB) }\end{array}$ & $\begin{array}{l}\text { Looking at another person and/or making eye contact. Head orientation should } \\
\text { also be considered when scoring this category. That is, the child's head should } \\
\text { be turned in the direction of the therapist or the canine. When the face of the } \\
\text { child cannot be seen, do not score this category. The item is also not scored } \\
\text { when the child is looking at an object worn by the therapist or the canine but } \\
\text { not at the therapist or the dog-for example, when the child is looking at the } \\
\text { name card of the therapy dog and focusing on the object but not the therapy } \\
\text { dog. In this case, a check should be made on "isolation" and not "eye contact". }\end{array}$ \\
\end{tabular}


Touch Instructions

Joint

Imitation

Wait

Initiation

Response

Social Verbal Behavior (SVB)

Verbal
Attention

Any non-accidental physical contact with the hands, such as petting, patting, holding and shaking hands. "Hug" is included in this item. That is, the child's arms encircle the therapist with a brief squeeze. If the touching behavior is in response to the therapist or a reaction to follow the therapist's instructions, then "touch" and "response" and "touch" and "follow instructions" are both checked, respectively. On the contrary, if the touching behavior is initiated by the child, only "touch" is checked. Do not check the item "initiation".

Doing what the therapist asks. The immediacy of the reaction should be considered. For example, if the therapist asks the child to take a toy apple from the table and child takes the toy apple at the 15-second mark, this category is checked. If the child does not respond to it immediately but does something else and then takes the toy apple from the table, this category is not checked, even if this behavior is observed at the 15 -second mark. In this example, the correctness of the targeted object is not checked. That is, it is fine for the child to take another type of toy fruit or more than one toy fruit. The causal relationship between the instruction and the behavior should also be considered.

The ability to coordinate attention between an object and a person in a social context. This includes (1) pointing, vague pointing, showing, calling the attention of another to an object or activity and (2) following pointing or a gaze. When the therapist asks the child to pay attention via pointing and the child follows the pointing, this category is scored. The category "following instructions" are not scored double in this case.

Imitating the behavior of the therapist, such as clapping hands after the therapist does. Another example is the therapist uses her fingers to count " 1,2 , 3 ", and the child does the same.

The child and the therapist share the same play material. The child is not occupied by play while the therapist is engaging in an activity. The child may look at the therapist or the activity, but this is not a requirement.

The child takes the initiative to play with the therapist and/or the therapy dog. For example, the child feeds the therapy dog water or child passes a ball to the therapist. This item is not checked when the child initiates play or activity without a social target-for example, if the child takes the initiative to do a puzzle. Instead, "isolation" behavior is marked. There is a great opportunity that the child touches the social targets when he/she initiates play with them. In this case, the item "touch" is not checked.

The child responds to the social target's behaviors, elicited either intentionally or unintentionally, with non-verbal behavior. For example, the child laughs when he/she sees the therapy dog yawn. Laughing is considered the child's response to the therapy dog; therefore, this item is checked.

Questioning The child asks the therapist questions, such as "Where is Coco?"

Response

The child responds to the social target's behavior, elicited either intentionally or unintentionally, with verbal behavior. For example, the child says "triangle" when the therapist shows the child a green triangle and a blue rectangle and asks, "Which color do you like, green or blue?" This item is checked even if the child gives a wrong answer to the therapist's question. In addition, if the child points at the green triangle while providing a verbal response, another check is marked on the item "response" as "pointing at" is considered as non-verbal response to the therapist.

Verbal The child repeats what the therapist said.

Imitation

Expression The child asks for an activity, a toy or an object.

of Needs

Sharing The child shares with the therapist with his/her feelings or thoughts. 


\begin{tabular}{|c|c|c|}
\hline \multirow[t]{3}{*}{$\begin{array}{l}2 . \\
\text { Non-social } \\
\text { Behavior } \\
\text { (NSB) }\end{array}$} & Isolation & $\begin{array}{l}\text { Any behavior that excludes the social targets, verbal or nonverbal. The child may look } \\
\text { blankly around the room without doing anything. The child may also play alone without the } \\
\text { involvement of the therapist or the dog. Making sounds or words with no clear intention to } \\
\text { communicate is also included in this sub-category. }\end{array}$ \\
\hline & $\begin{array}{l}\text { Autistic } \\
\text { Features }\end{array}$ & $\begin{array}{l}\text { Specific autistic behavior is included in this sub-category. It includes self-stimulatory } \\
\text { behavior and obsessive compulsive behavior-specifically, covering ears, hand-flapping, } \\
\text { failing to respond to their name being called, staring blankly into space, and blunt affect. }\end{array}$ \\
\hline & $\begin{array}{l}\text { Negative } \\
\text { Behavior }\end{array}$ & $\begin{array}{l}\text { This sub-category is marked when behavior indicates strong protests against becoming } \\
\text { socially engaged with social targets or this is the child's means to initiate contact with the } \\
\text { social targets. Included are the following behaviors: } 1 \text {. crying/screaming in response to the } \\
\text { social targets; } 2 \text {. having a tantrum, } 3 \text {. physical withdrawal/moving and turning away from } \\
\text { social targets, } 4 \text {. rejecting social targets' intervention; } 5 \text {. biting, hitting, kicking and pushing } \\
\text { with force, and } 6 \text {. throwing objects at another person. }\end{array}$ \\
\hline 3. Others & \multicolumn{2}{|c|}{$\begin{array}{l}\text { Behaviors that are excluded from the above categories are included in this category. Examples are shifting } \\
\text { attention from one activity to another, sneezing, or coughing. }\end{array}$} \\
\hline $\begin{array}{l}4 . \quad \text { Not } \\
\text { observed }\end{array}$ & \multicolumn{2}{|c|}{ Behaviors that could not be observed or captured are included in this category. } \\
\hline
\end{tabular}

\subsection{Coders}

Two undergraduate students, who passed the three selection criteria (having no fears or phobias of animals, no history of negative experiences with animals, and no pets) were recruited to be the coders. They were blind to the experimental predictions. Prior to the formal coding of 230 twenty-minute sessions, issues of confidentiality were highlighted, and systematic training was conducted. The coders started their work independently only after $87 \%$ intercoder agreement on their trials was reached.

\subsection{Intercoder Reliability}

Intercoder reliability was calculated based on $15 \%$ of the analyzed 230 videotaped sessions, which were selected randomly and coded again by a second coder. That is, if the selected session was originally coded by Coder A, Coder B needed to code it again. Intercoder agreement was calculated using a total agreement approach. The researcher summed the total number of responses coded by each coder, divided the smaller total by the larger total, and multiplied the amount by $100 \%$. The results of the intercoder agreement has been reported in a published paper (Fung \& Leung, 2014). The intercoder agreement in the two broad behavioral categories, i.e., SB and NSB, was $97.9 \%$ and $99.3 \%$, respectively.

\subsection{Data Analysis}

The data analysis was based on the percentage of intervals during which SB (including VSB and NVSB) and NSB were observed during 4 assessment periods. The periods included the baseline period (sessions $1-3$ ), the treatment period (Phase 1: sessions 4 and 5; Phase 2: sessions 6-10; Phase 3: sessions $11-15$; Phase 4: sessions 16 and 17), the post-treatment period (sessions $18-20$ ), and the follow-up period (sessions $21-23$ ). Data were graphed as a percentage of intervals, and changes in the levels and trends were inspected visually, consistent with the A-B-A methodology (Kennedy, 2005). In addition, videotapes of the sessions were reviewed to identify examples of participants' behaviors that were coded in the observational system. Relevant examples are cited in the Discussion section to illustrate significant quantitative results.

\section{Results}

\subsection{Social Behavior (SB)}

As a general estimate of treatment effectiveness, the overall rates of SB were calculated. During the baseline sessions, Leon exhibited SB in $49.7 \%$ of the 15 -second intervals. This value increased to $65 \%$ by the end of treatment. The benefits of intervention disappeared at follow-up, with Leon exhibiting SB in $49.7 \%$ of intervals. Meanwhile, the percentage of intervals in which William presented SB at baseline was $23.7 \%$, a value that had increased to $33.7 \%$ by the post-treatment assessment. The benefits of therapy were still evident at follow-up, with William exhibiting SB in 33.3\% of intervals (Figure 1). 


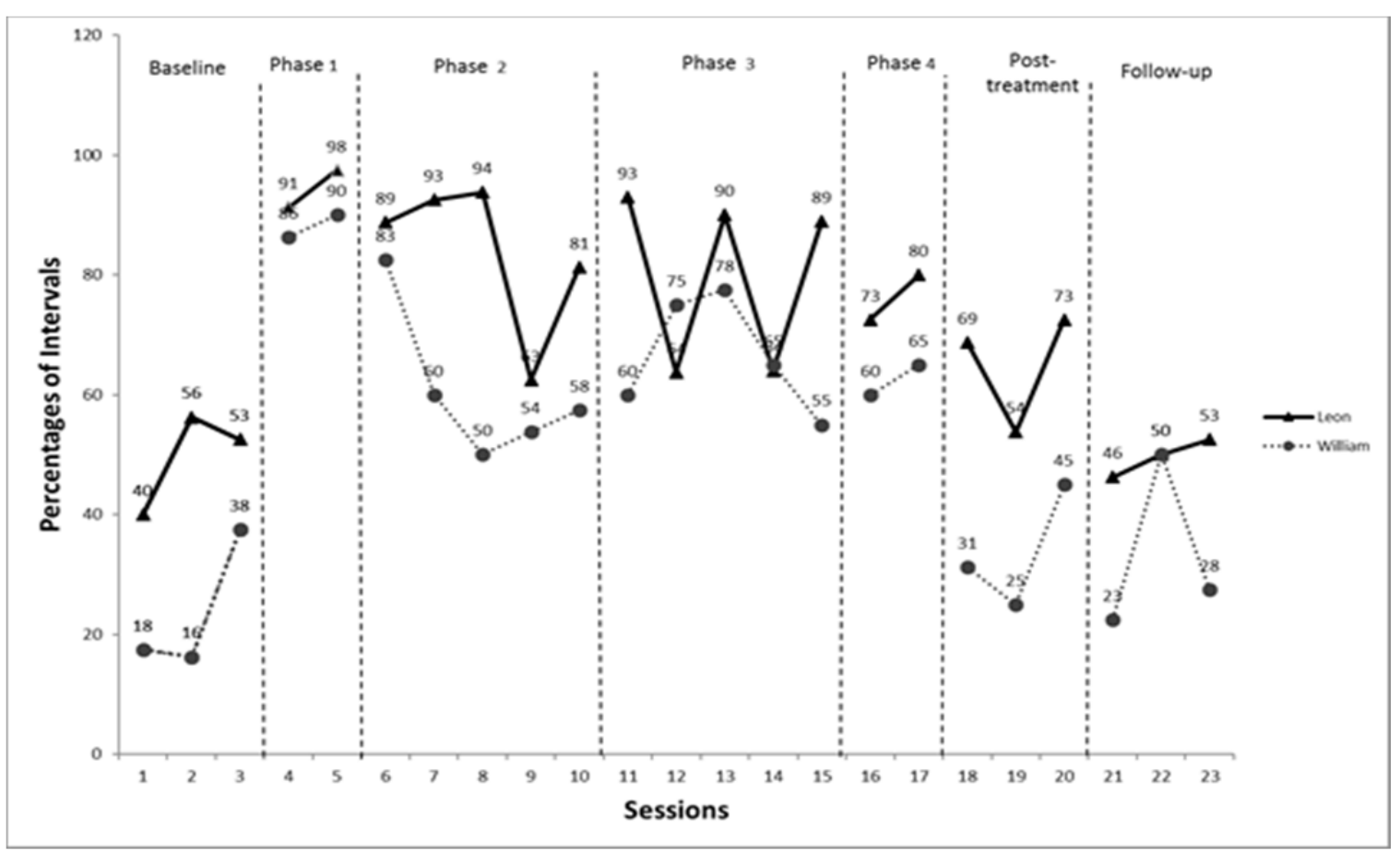

Figure 1. The percentages for intervals during which Leon and William exhibited SB at baseline, during each treatment phase, posttreatment, and at follow-up

Figure 1 shows that the pattern of changes in SB throughout all phases was similar for Leon and William. Their SB greatly increased, to $94.5 \%$ (Leon) and $88 \%$ (William), from baseline to Phase 1; then, a steady drop occurred in the subsequent treatment phases. Compared to the baseline measurement, there was a $34.1 \%$ (Leon) and $37.1 \%$ (William) increase in Phase 2, a 30.3\% (Leon) and 42.9\% (William) increase in Phase 3, and a 26.8\% (Leon) and $38.8 \%$ (William) increase in Phase 4. The average increases in SB in Phases 2, 3, and 4 were $30.4 \%$ for Leon and $39.6 \%$ for William. Finally, the decreasing trend continued to the post-treatment phase and the follow-up phase, as depicted in the above paragraph.

\subsection{Non-Social Behavior (NSB)}

During the baseline phase, Leon and William exhibited isolative behavior in $44 \%$ and $75 \%$ of intervals, respectively. During Phase 1 of treatment, the values were both strikingly lower, at $4 \%$. Although their isolative behavior increased over the course of treatment, its rate continued to be lower than at baseline, with values of $15 \%$, $19 \%$ and $22 \%$ for Leon and $38 \%, 31 \%$ and $34 \%$ for William at Phase 2, Phase 3 and Phase 4, respectively. The value of Leon's isolative behavior at post-treatment (31\%) was still lower than at baseline, while a slightly increased value was found at follow-up (49\%). William's isolative behavior at post-treatment and follow-up continued to be lower than at baseline, with values of $62 \%$ and $63 \%$ of intervals, respectively (Figure 2). Both autistic features and negative behaviors toward the therapist were rare for Leon and William, occurring in $0 \%$ to $1 \%$ of all intervals (Figure 2). 


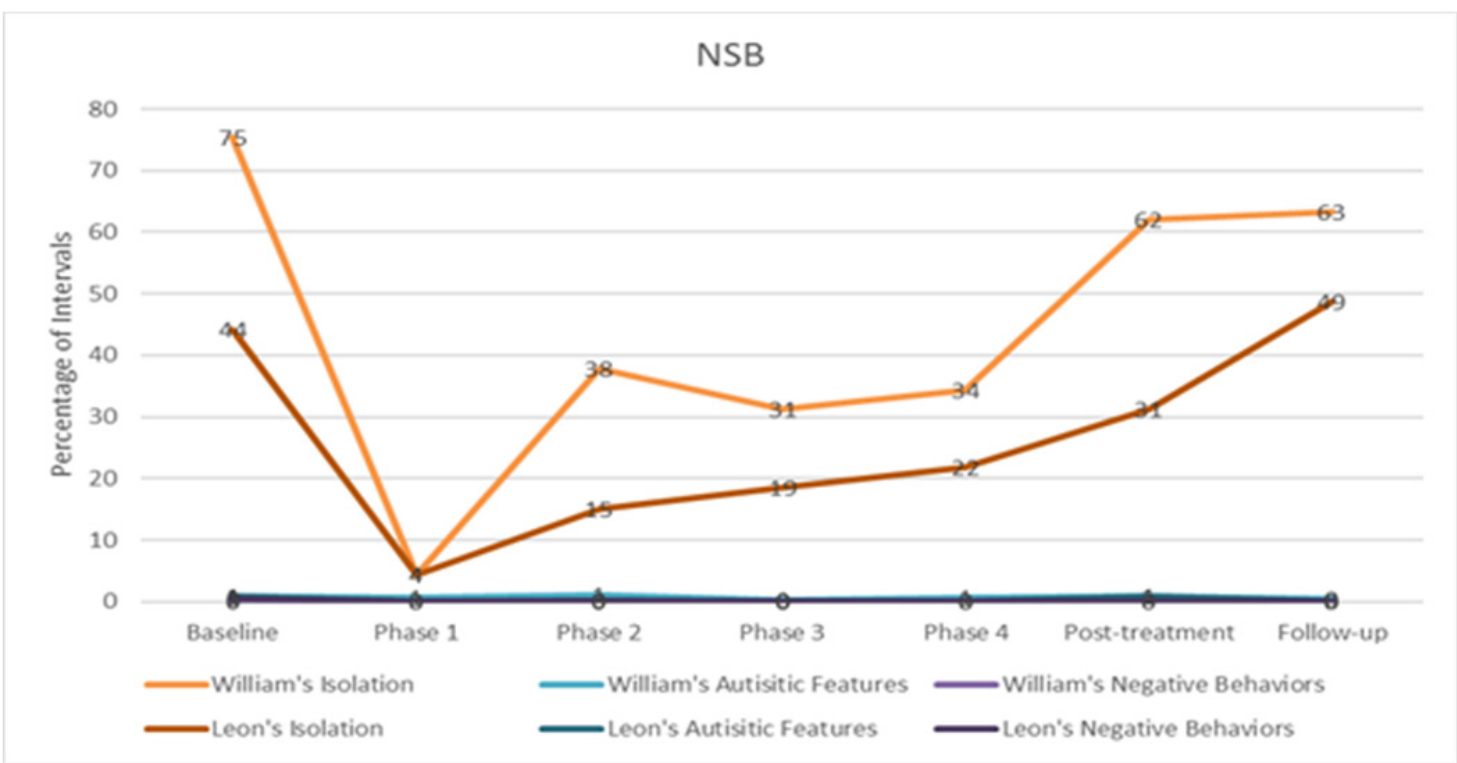

Figure 2. The average percentages for intervals during which Leon and William exhibited each category of NSB at baseline, during each treatment phase, posttreatment, and at follow-up

\subsection{Verbal Social Behavior (VSB)}

Leon presented VSB in $23 \%$ of intervals during the baseline phase. During Phase 1 of treatment, the value increased by $20 \%$, to $43 \%$. His VSB continued to be higher than at baseline, with values of $36 \%, 37 \%$ and $34 \%$ at Phase 2, Phase 3 and Phase 4, respectively. The value of Leon's VSB at post-treatment (46\%) was observed to be the highest value across all phases. The increased VSB was still evident at follow-up, with Leon exhibiting VSB in $32 \%$ of intervals (Figure 3). Leon's VSB showed 3 patterns. First, verbal imitation and expression of needs had a very low occurrence. Second, sharing was particularly frequent at post-treatment. Finally, questioning increased in phases 1 and 2 (Figure 3).

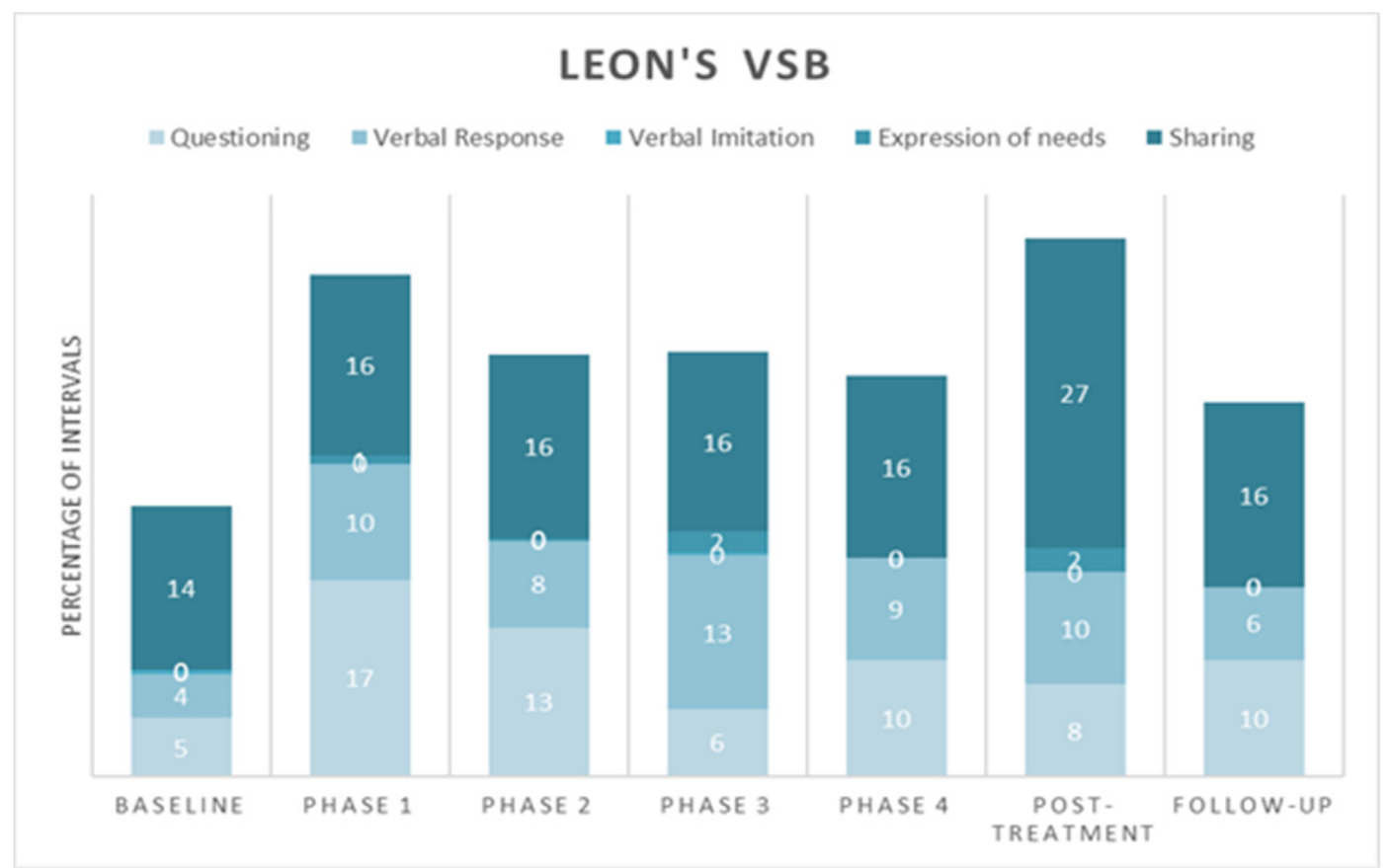

Figure 3. The average percentages for intervals during which Leon exhibited each category of VSB at baseline, during each treatment phase, posttreatment, and at follow-up 
William's VSB was observed to be infrequent at baseline (6\%), Phase $1(8 \%)$, Phase $2(4 \%)$ and Phase $3(6 \%)$. In Phase 4, William's VSB increased to $19 \%$ of intervals. In this phase, both questioning and sharing were more frequent. Hereafter, the increased VSB disappeared at post-treatment, with William exhibiting VSB in $9 \%$ of intervals. During follow-up, his VSB increased to 13\% of intervals (Figure 4). In addition, William's VSB had the same pattern as Leon's, i.e., verbal imitation and expression of needs had very low occurrence (Figure 4).

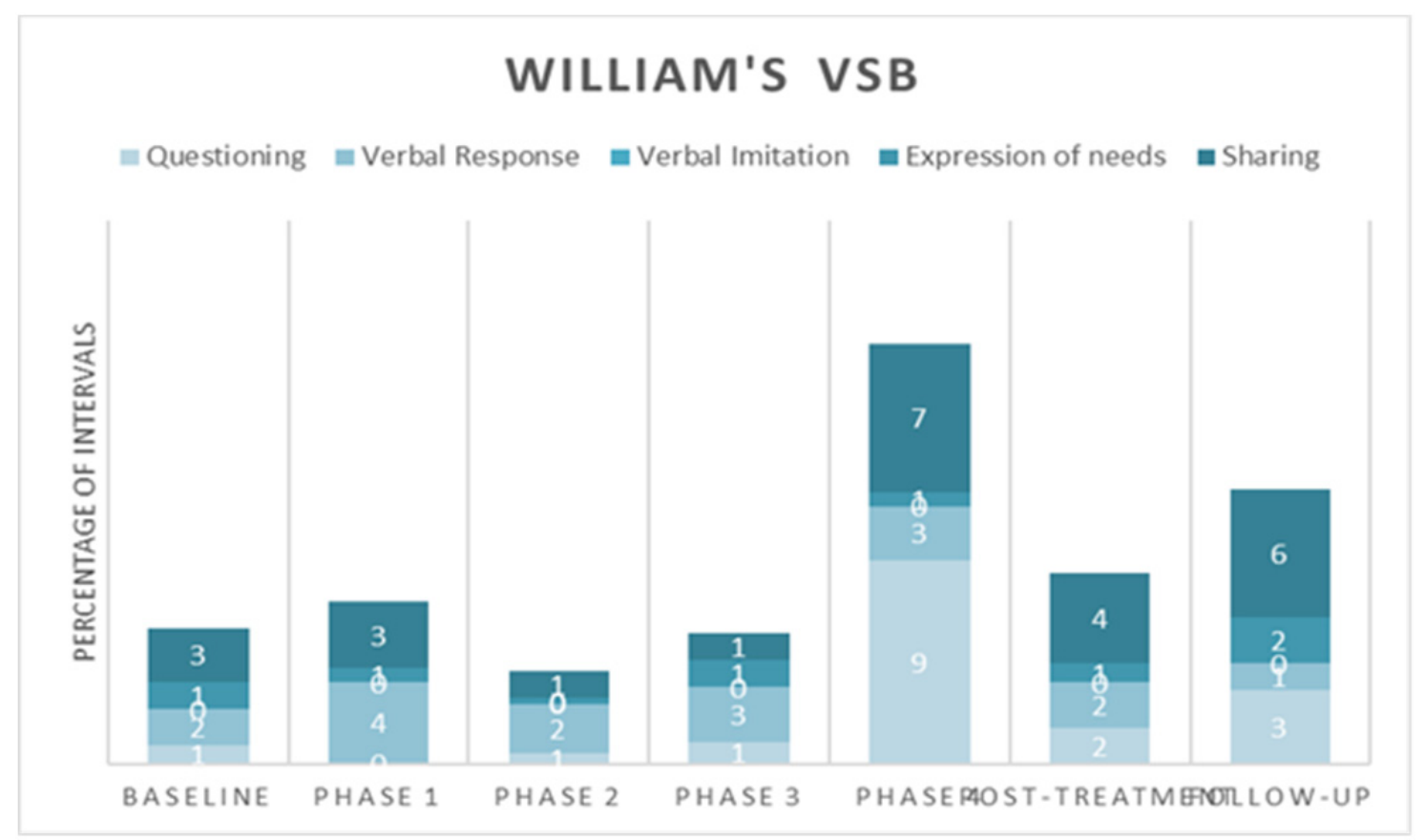

Figure 4. The average percentages for intervals during which William exhibited each category of VSB at baseline, during each treatment phase, posttreatment, and at follow-up

\subsection{Non-Verbal Social Behavior (NVSB)}

Leon exhibited NVSB in $30 \%$ of intervals during the baseline phase. His NVSBs, which were mainly eye contact, waiting and joint attention, increased over the course of treatment. Its rate continued to be higher than at baseline, with values of $49 \%, 54 \%, 67 \%$ and $64 \%$ at Phase 1 , Phase 2, Phase 3 and Phase 4 , respectively. The increased NVSB disappeared at post-treatment and follow-up, with Leon exhibiting NVSB in $22 \%$ of intervals, which was lower than the baseline. In addition, Leon displayed few initiations at the treatment phase and no imitations or touch at any phase (Figure 5). 


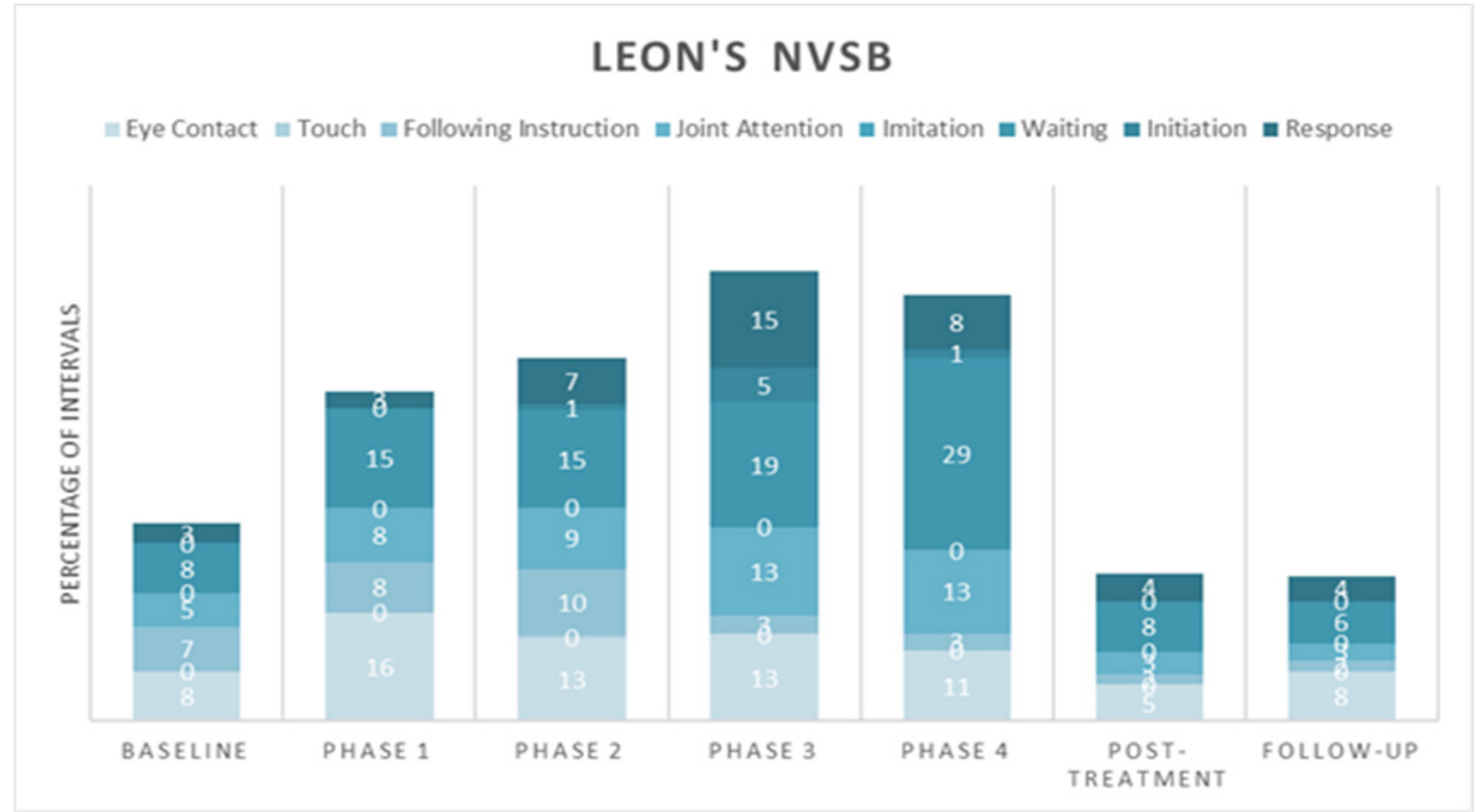

Figure 5. The average percentages for intervals during which Leon exhibited each category of NVSB at baseline, during each treatment phase, posttreatment, and at follow-up

William's NVSB displayed 4 characteristics. First, his NVSB increased from baseline to treatment, with values of $25 \%, 40 \%, 37 \%$ and $64 \%$ at Phase 1, Phase 2, Phase 3 and Phase 4, respectively. Second, the increased NVSB disappeared at post-treatment and follow-up, though it was higher than at baseline, with William exhibiting NVSB in $28 \%$ and $23 \%$ of intervals, respectively. Third, William seldom elicited initiation or imitation throughout all phases. Finally, William's NVSBs, which were mainly eye contact, waiting and joint attention, were especially frequent in Phase 4 (Figure 6).

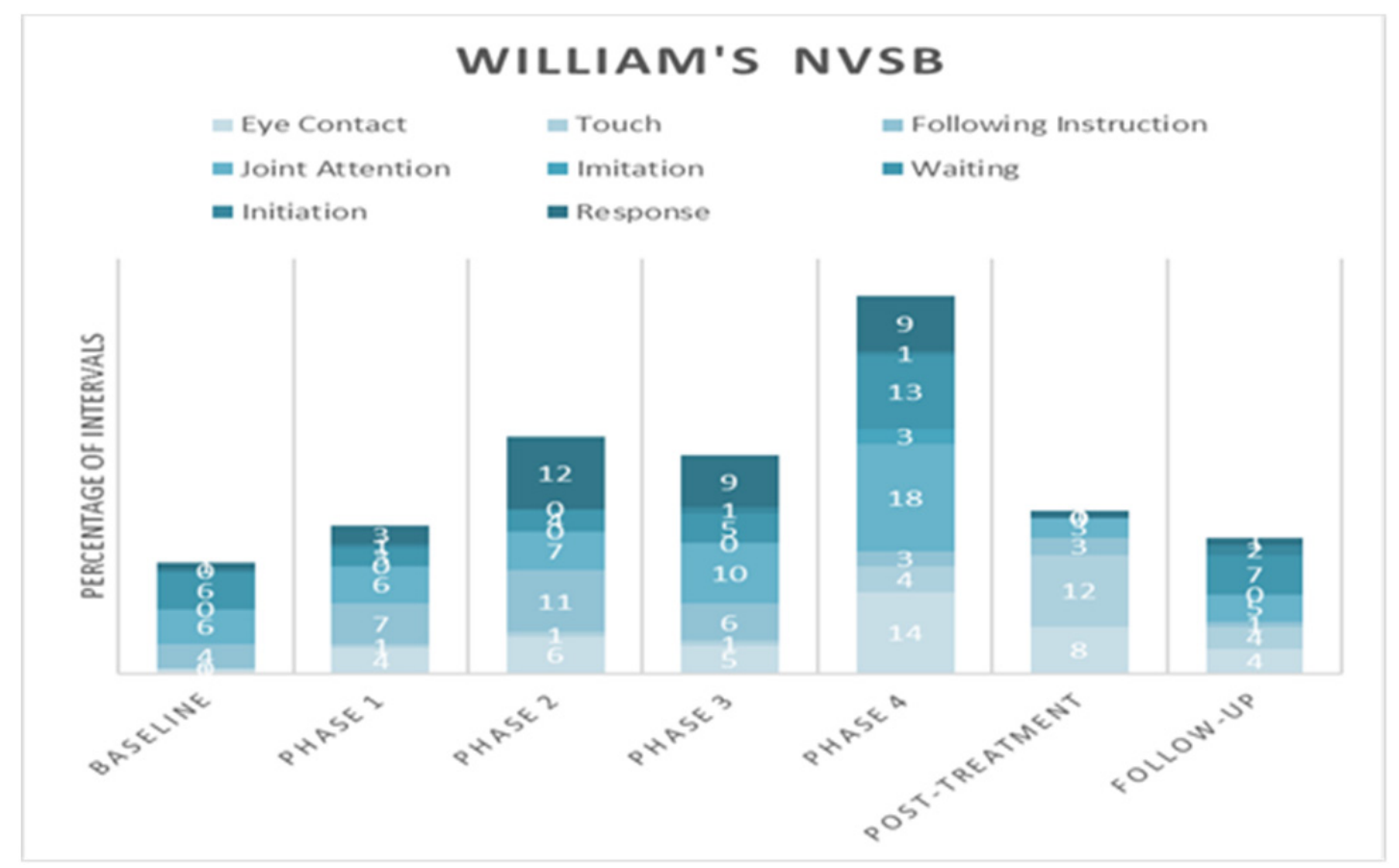

Figure 6. The average percentages for intervals during which William exhibited each category of NVSB at baseline, during each treatment phase, posttreatment, and at follow-up 


\section{Discussion}

Considering CAAT is often used in practice without being documented systematically, this paper aimed to take the first steps toward documenting existing practice-specifically, the treatment manual and the research protocol used - to stimulate replication and further studies. By utilizing a detailed coding system, the social behaviors of two boys with ASD (Leon and William) who participated in a structured, interactive CAPT intervention were observed and analyzed throughout the baseline, treatment, post-treatment and follow-up phases. The results of the case studies showed that the CAPT intervention slightly increased the social behaviors of Leon and William, by $15 \%$ and $10 \%$, respectively, immediately after treatment. After one month, a stranger was arranged to replace the therapist at the follow-up measurement. Leon's social behavior had decreased and returned to the baseline level, whereas William's social behavior remained higher than that at the baseline phase. Overall, the findings provide positive support for using CAPT as an intervention to facilitate the social communication of children with autism. The outcomes of the two cases lend support to findings from previous observational AAT studies with the ASD population (Krskova et al., 2010; Martin \& Farnum, 2002; Redefer \& Goodman, 1989; Sams et al., 2006; Silva et al., 2011). In addition to the above overall picture of the effectiveness of CAPT, some findings from the coding results are worth noting and discussing. The findings about the social communication of Leon and William provide a more detailed picture of an intervention in which a therapy canine was incorporated into a structured play context.

First, it was found that the isolative behavior of Leon and William strikingly decreased when Coco, the therapy canine, was first introduced. Coco seemed to immediately stimulate the social interest of Leon and William. This social facilitation effect of a therapy canine has been previously identified by researchers, who have called therapy animals a "social lubricant" (Corson \& Corson, 1980), a "social ice-breaker" (Erickson, 1985), a "social catalyst" (Chandler, 2011) and a "speech elicitor" (Fung \& Leung, 2014). Based on the immediate social interest on a therapy canine, the present CAPT intervention planned to lead the children with ASD to engage in three 6-minute activities to interact directly with Coco. It aimed to build the child-canine relationship with the assistance of the therapist in the first phase of the CAPT. Specifically, they learned to name and identify Coco's body parts, cleaned Coco, fed her water and treats, and were given time to pet her. It is very likely that the directive, structured play intervention further enhanced this social facilitating effect and explained the great reduction in their isolative behaviors.

Second, there was an increasing trend of the non-verbal social behaviors of Leon and William from baseline to all treatment phases. A closer look at the increased non-verbal social behaviors revealed that they elicited more reciprocal interaction with the therapist. Specifically, Leon and William looked at the therapist more, waited their turns in different interactive play with the therapist more, and elicited more joint attention over the CAPT treatment. As clearly stated in the treatment manual, the main objective of the intervention was to involve children with ASD in interactive activities. With this objective in mind, two codes-joint attention and waiting-were specifically developed to measure the reciprocal interaction of children with ASD. These results seem to be logical consequences of the current CAPT intervention, in which various interactive activities were arranged with the emphasis on turn-taking play skills.

Third, the two children with ASD elicited more verbal languages. Specifically, they elicited more initiative speech (i.e., they asked more questions and shared their feelings and concerns more with the therapist). However, this speech-eliciting effect manifested at different phases and for different communicative functions in Leon and William. It is likely that these differences were the result of Leon and William's different verbal ability levels. Leon's verbal skills were assessed as mild delay, and he could talk about and ask for things spontaneously. Leon asked many Coco-related questions of the therapist in phases 1 and 2. All Leon's questions in these two phases were then analyzed and finally summarized as four themes: 1. human-animal interaction: Will you blame her?, Does she hit people?, and Did she bite you?; 2. canine's body features: Why it (the mouth/the teeth) is black?, Why so dirty (the mouth)? and Why Coco so smelly?; 3. daily practices: Use what kind of tooth brush?, Where to go for shower?, Why could (we) comb the dog's hairs? and Will you (the therapist) bring Coco at work?; and 4. imaginary questions: How to do operation (for dog)?, Will (she) wake up after the operation?, Why people don't have tails? and Why a bus not allow dog to take on? Obviously, the introduction of the therapy canine elicited Leon's curiosity about this living thing. After baseline measurements, Leon spoke more at all phases. William's case was different. He showed a moderate delay in verbal ability and did not express himself well by verbal language. His verbal language increased only until phase 4 , in which Coco was faded out in the intervention. In order to understand this specific finding, his VSB codes in phase 4 (sessions 16 and 17) were further examined. Twenty-four out of 31 codes were identified as Coco related. William asked the therapist questions, for example, Is Coco coming? Where is Coco? Coco Monday, how about? Is Coco cutting pepper (William's favorite game)? and Coco going home? 
William also shared with the therapist his wishes. He said, Wait Coco play, Find Coco come here, and Coco is coming. This examination revealed that the William's latent speech was elicited by his wishes of playing with Coco again. Moreover, this discovery implied that it was an ethical measure to include phase 4, in which 2 sessions of child-therapist interactions with a diminishing presence of the canine were designed. Regardless of whether participants have difficulties with transitions, sudden fading out of therapy canine should be avoided.

Fourth, seven specific behaviors were rarely observed throughout all phases for Leon and William. These include autistic features, negative behaviors, repeating what the therapist said, asking the therapist for an activity, a toy or an object, physical contact with the therapist, imitating the behavior of the therapist and taking the initiative to play with the therapist. The rare occurrence of these social and non-social behaviors reflected that the children did not have any needs and/or they were not facilitated to perform those behaviors in all stages. The current CAPT treatment design could be used to examine and understand these findings. As stated by Fenichel (1976), "disorganized children need someone to organize their world for them......training that can bring order, stability and direction to minds that are disorganized, unstable and unpredictable" (p.220). Rutter (1985) supported this position and further suggested that psychosocial programs to remediate the social deficits of children with ASD should provide planned periods of structured social interaction. It is possible that the structured physical environment, visual support, steady and slowly switching, and notice about transitions in advance made the play context predictable and comprehensible, and therefore, the treatment did not stimuli their negative behaviors and autistic features. It is also possible that the interactive play with the canine and the therapist appropriately addressed the cognitive level, play skills deficits and different interests of the two children with ASD, and thus, it was not necessary to behave negatively. Another possible explanation was that the current structured and directive CAPT intervention was not favorable to elicit some social behaviors, such as physical contact with the therapist, taking the initiative to play with the therapist, imitating the behavior of the therapist, and asking the therapist for an activity, a toy or an object.

Last but not least, it was found that the increasing trend of non-verbal social behaviors of both participants stopped in the post-treatment and follow-up phases. During treatment Phase 4, both Leon and William exhibited non-verbal social behaviors in $64 \%$ of intervals, which was almost the highest frequency of social behaviors elicited by the two children in the whole study (the highest was $67 \%$ of intervals). Then, the percentage dropped significantly, to $22 \%$ and $28 \%$, for Leon and William, respectively, from treatment Phase 4 to the post-treatment phase. This finding deserves attention. The difference between the two phases explained the great reduction in social behaviors at the post-treatment phase. Upon examining the two phases, it was believed that the design of the post-treatment measure made the greatest difference. As mentioned, the natural occurrence of social behavior in the free play context was measured in the post-treatment stage. Each post-treatment session contained a 6-minute therapist-passive condition, a 6-minute therapist-active condition, and a 6-minute therapist-passive condition. This design tends to require high capability and motivation for initiation for participating children. In the present adult-directed CAPT intervention, though Leon and William elicited more reciprocal interaction, they rarely took the initiative to play with the therapist. Therefore, in the current post-treatment context, the effectiveness of the CAPT intervention could not be fairly measured. It is proposed that the current post-treatment measure should be revised to a design with a 9-minute therapist-active condition and then a 9-minute therapist-passive condition. The change would not only allocate one half of the post-treatment time to the therapist-active condition but also put this condition before therapist-passive condition. It is hoped that the children would be involved in the interactive play in the first half of the session and then continue the interaction in the therapist-passive condition.

The evidence revealed that initial efficacy studies of AAI, as a new psychosocial intervention for ASD, have complied, enabling it to become established as promising (O'Haire, 2013). As recommended by Smith et al., (2007), resources should be dedicated to outlining promising interventions into a manual that undergoes pilot testing. This paper is an attempt to respond to the call to move AAI from the preliminary testing phase to systematic manualization. In the present study, CAPT was identified as a main intervention type of AAI, and it is worth focusing on its development. The CAPT manual and coding manual disseminated in this paper were developed and utilized in a randomized controlled trial of CAPT intervention, which resulted in statistically significant increases in the verbal social behavior of a group of children with autism (Fung \& Leung, 2014). Specifically, the CAPT manual was developed for elementary-aged children with ASD who are within the low-mild range of mental deficiency and possess verbal ability. The case studies presented in this paper systematically studied the changes in the social behavior of two boys with ASD across 23 sessions of a planned CAPT intervention. By utilizing the present coding system, which included typical and ASD-specific behavioral categories, the case studies collected in-depth data of the effect for two children with ASD, which are valuable to understand how the structured, interactive CAPT treatment addressed the key features of ASD (for example, visual 
learning and difficulty switching between activities) and target behaviors (for example, turn-taking and social reciprocity). This study took the first steps toward making CAPT treatment manuals and research protocol available to a wider audience. Further effort to promote the development of a CAPT manual and protocol is warranted.

\section{Acknowledgments}

I am grateful to the Animals Asia Foundation for their professional support of providing their Dr Dogs as the therapy dogs in the study. I am also indebted to the Hong Chi Morninghope School Tuen Mun. Without the participation of the children with autism and their families at the School, the study would not be made possible.

\section{Funding}

The work described in this paper was partially supported by the Research Support Scheme 2016/2017 of the Department of Special Education and Counselling at the Education University of Hong Kong.

\section{Competing Interests Statement}

The author declares that she has no competing or potential conflicts of interest.

\section{References}

American Psychiatric Association. (1994). Diagnostic and statistical manual of mental disorders (4th ed.). Washington, DC: American Psychiatric Association.

American Psychiatric Association. (2013). Diagnostic and statistical manual of mental disorders (5th ed.). Washington, DC: American Psychiatric Association. https://doi.org/10.1176/appi.books. 9780890425596

Bass, M. M., Duchowny, C. A., \& Llabre, M. M. (2009). The effect of therapeutic horseback riding on social functioning in children with autism. Journal of Autism and Developmental Disorders, 39(9), 1261-1267. https://doi.org/10.1007/s10803-009-0734-3

Berry, A., Borgi, M., Francia, N., Alleva, E., \& Cirulli, F. (2013). Use of Assistance and Therapy Dogs for Children with Autism Spectrum Disorders: A Critical Review of the Current Evidence. The Journal of Alternative and Complementary Medicine, 19(2), 73-80. https://doi.org/10.1089/acm.2011.0835

Burrows, K. E., Adams, C. L., \& Spiers, J. (2008). Sentinels of safety: Service dogs ensure safety and enhance freedom and well-being for families with autistic children. Qualitative Health Research, 18(12), 1642-1649. https://doi.org/10.1177/1049732308327088

Chandler, C. K. (2011). Animal assisted therapy in counseling (2nd ed.). New York, NY: Routledge.

Corson, S., \& Corson, E. (1980). Pet animals as nonverbal communication mediators in psychotherapy in institutional settings. In S. Corson \& E. Corson (Eds.), Ethology and nonverbal communicationin mental health (pp. 83-110). Oxford: Pergamon Press.

Davis, T. N., Scalzo, R., Butler, E., Stauffer, M., Farah, Y. N., Perez, S., Mainor, K., Clark, C., Miller, S., Kobylecky, A., \& Coviello, L. (2015). Animal Assisted Interventions for Children with Autism Spectrum Disorder: A Systematic Review. Education and Training in Autism and Developmental Disabilities, 50(3), 316-329.

Erickson, R. (1985). Companion animals and the elderly. Geriatric Nursing, 6, 92-96. https://doi.org/10.1016/S0197-4572(85)80006-9

Esposito, L., Mccardle, P., Maholmes, V., McCune, S., \& Griffin, J. A. (2011). Introduction. In P. McCardle, S. McCune, J. A. Griffin, L. Esposito, \& L. S. Freund (Eds.), Animals in our lives: Human-animal interaction in family, community, and therapeutic settings (pp. 1-5). Baltimore, MD: Brooles Publishing Co. https://doi.org/10.4337/9781849809115.00005

Fenichel, R. (1976). Socializing the severely disturbed child. In E. Schopler \& R. J. Reichler (Eds.), Psycho-pathology and child development: Research and treatment. New York: Plenum Press. https://doi.org/10.1007/978-1-4684-2187-3_13

Fung, S.C. (2016). Canine-assisted Reading Programs for Children with Special Educational Needs: Rationale and Recommendations for the Use of Dogs in Assisting Learning. Educational Review. https://doi.org/10.1080/00131911.2016.1228611

Fung, S. C., \& Leung, S. M. (2014). Pilot study investigating the role of therapy dogs in facilitating social interaction among children with autism. Journal of Contemporary Psychotherapy, 44(4), 253-262. 
https://doi.org/10.1007/s10879-014-9274-z

Gabriels, R. L., Agnew, J. A., Holt, K. D., Shoffner, A., Zhaoxing, P., Ruzzano, S., . . Mesibov, G. (2012). Pilot study measuring the effects of therapeutic horseback riding on school-age children and adolescents with autism spectrum disorders. Research in Autism Spectrum Disorders, 6(2), 578-588. https://doi.org/10.1016/j.rasd.2011.09.007

Gabriels, R. L., Pan, Z., Dechant, B., Agnew, J. A., Brim, N., \& Mesibov, G. (2015). Randomized controlled trial of therapeutic horseback riding in children and adolescents with autism spectrum disorder. Journal of the American Academy of Child and Adolescent Psychiatry, 54(7), 541-549. https://doi.org/10.1016/j.jaac.2015.04.007

Garcia-Gomez, A., Risco, L. M., Rubio, J. C., Guerrero, E., \& Garcia-Pena, I. M. (2014). Effects of a program of adapted therapeutic horse-riding in a group of autism spectrum disorder children. Electronic Journal of Research in Educational Psychology, 12(1), 107-128. https://doi.org/10.14204/ejrep. 32.13115

Hoagwood, K. E., Acri, M., Morrissey, M., \& Peth-Pierce, R. (2016). Animal-assisted therapies for youth with or at risk for mental health problems: A systematic review. Applied Developmental Science. https://doi.org/10.1080/10888691.2015.1134267

Issacs, J. M. (1998). The effects of pet-facilitated therapy on the social and interactive behaviors of autistic children. Master's thesis. California State University, Long Beach.

Jenkins, S. R., \& DiGennaro Reed, F. D. (2013). An experimental analysis of the effects of therapeutic horseback riding on the behavior of children with autism. Research in Autism Spectrum Disorders, 7, 721-740. https://doi.org/10.1016/j.rasd. 2013.02.008

Keino, H., Funahashi, A., Keino, H., Miwa, C., Hosokawa, M., \& Hayashi, Y. (2009). Psycho-educational horseback riding to facilitate communication ability of children with pervasive developmental disorders. Journal of Equine Science, 20(4), 79-88. https://doi.org/10.1294/jes.20.79

Kennedy, C. H. (2005). Single-case designs for educational research. Boston, MA: Pearson.

Kern, J. K., Fletcher, C. L., Garver, C. R., Mehta, J. A., Grannemann, B. D., Knox, K. R., . . Trivedi, M. H. (2011). Prospective trial of equine-assisted activities in autism spectrum disorder. Alternative Therapies in Health and Medicine, 17(3), 14-20.

Krs`kova', L., Talarovičova', A., \& Olexova', L. (2010). Guinea pigs-The "small great" therapist for autistic children, or: Do guinea pigs have positive effects on autistic child social behavior? Society and Animals, 18, 139-151. https://doi.org/10.1163/156853010X491999

Lanning, B. A., Baier, M. E., Ivey-Hatz, J., Krenek, N., \& Tubbs, J. D. (2014). Effects of equine assisted activities on autism spectrum disorder. Journal of Autism and Developmental Disorders, 44(8), 1897-1907. https://doi.org/10.1007/s10803-014-2062-5

Martin, F., \& Farnum, J. (2002). Animal-assisted therapy for children with pervasive developmental disorders. Western Journal of Nursing Research, 24, 657-670. https://doi.org/10.1177/019394502320555403

Maujean, A., Pepping, C. A., \& Kendall, E. (2015). A Systematic Review of Randomized Controlled Trials of Animal-Assisted Therapy on Psychosocial Outcomes. Anthrozoös, 28(1), 23-36. https://doi.org/10.2752/089279315X14129350721812

Memishevikj, H., \& Hodzhikj, S. (2010). The effects of equine-assisted therapy in improving the psychosocial functioning of children with autism. Journal of Special Education and Rehabilitation, 11, 57-67.

Nimer, J. and Lundahl, B. (2007). Animal-assisted therapy: a meta-analysis. Anthrozoös, 20(3), 225-238. https://doi.org/10.2752/089279307X224773

Nugent, W. R. (1996). Integrating single-case and group-comparison designs for evaluation research. Journal of Applied Behavioral Science, 32(2), 209-226. https://doi.org/10.1177/0021886396322007

O'Haire, M. E. (2013). Animal-assisted intervention for autism Spectrum disorder: A systematic literature review. Journal of Autism and Developmental Disorders, 43, 1606-1622. https://doi.org/10.1007/s10803-012-1707-5

Professional Association of Therapeutic Horsemanship International. (2016). EAAT Definitions. Retrieved July 26, 2016, from http://www.pathintl.org/resources-education/faculty/27-resources/general/193-eaatdefinitions

Redefer, L. A., \& Goodman, J. F. (1989). Brief report: Pet-facilitated therapy with autistic children. Journal of 
Autism and Developmental Disorders, 19(3), 461-467. https://doi.org/10.1007/BF02212943

Rutter, M. (1985). The treatment of autistic children. Journal of Child Psychology and Psychiatry and Allied Disciplines, 26, 193-214. https://doi.org/10.1111/j.1469-7610.1985.tb02260.x

Sams, M. J., Fortney, E. V., \& Willenbring, S. (2006). Occupational therapy incorporating animals for children with autism: A pilot investigation. The American Journal of Occupational Therapy, 60, 268-274. https://doi.org/10.5014/ajot.60.3.268

Silva, K., Correia, R., Lima, M., Magalha es, A., \& de Sousa, L. (2011). Can dogs prime autistic children for therapy? Evidence from a single case study. Journal of Alternative and Complementary Medicine, 17(7), 1-5. https://doi.org/10.1089/acm.2010.0436

Smith, T., Scahill, L., Dawson, G., Guthrie, D., Lord, C., \& Odom, S. (2007). Designing research studies on psychosocial interventions in autism. Journal of Autism and Developmental Disorders, 37(2), 354-366. https://doi.org/10.1007/s10803-006-0173-3

\section{Copyrights}

Copyright for this article is retained by the author(s), with first publication rights granted to the journal.

This is an open-access article distributed under the terms and conditions of the Creative Commons Attribution license (http://creativecommons.org/licenses/by/4.0/). 